\title{
Scientific Law and Human Will
}

\author{
Yun-Fei ZHANG \\ yunfei_zh@sina.com \\ School of Marxism, Yanshan University, Qinhuangdao 066004, China
}

Keyword: Scientific Law, Scientific Prediction, Human Will

\begin{abstract}
Scientific law is the roadmap with which human can put their will into the nature. There are two points for understanding this proposition. Firstly, the final goal of developing science is for human will which can be put into the nature. Secondly, human will change the scientific law. The modality and form of laws have a close relationship with human will.

Natural science and human science have always been regarded as two mutually distinct and separated fields. They have different research objects and methods. Different from the human science, the natural science emphasizes the universality and the confirmation of the research results, and obtains the understanding of the regularity of the nature in the course of the study. The Scientific laws use objectivity as a benchmark. In front of the scientific laws, the human will have no place to active. In this paper, we question this kind of views and research status, trying to explore the role of human will in the course of natural science research.
\end{abstract}

\section{Scientific Law and Its Forecast Function}

Under the excitation of scientific spirit and method, the paradigm of modern humanities occurred two historic turns. The first turn is to imitate natural science to study humanities. Just as Hegel once thought that: "To help to bring philosophy nearer to the form of science-that goal where it can lay aside the name of love of knowledge and be actual knowledge-that is what I have set before me." [1] In twentieth Century, Russell had a dream: "I liked to think of the applications of mathematics to the physical world, and I hoped that in time there would be a mathematic of human behavior as precise as the mathematics of machines." [2]

Human science blindly seeks their own scientific mode, but the object and methods of humanities are fundamentally different from natural science. Then, the human science is like a lost ship in the song of Siren. To walk out of predicament, the humanities began to seek and establish its own unique quality distinguished with natural science. This can be called the second turn of humanities research paradigm. In the second turn, Dilthey and Rickert are the representative characters. Dilthey's lifelong concern was to establish a proper theoretical and methodological foundation for the "human sciences" (e.g. history, law, literary criticism), distinct from, but equally "scientific" as, the "natural sciences" (e.g. physics, chemistry). Dilthey put forward the term Geisteswissenschaft (literally, "science of the mind" or "spiritual knowledge"). He believes the main object of spiritual knowledge includes the life of mental ability, but natural sciences mainly for the study of nature; spiritual knowledge mainly studies the meaning relations in the life world, but natural science mainly study the cause and effect relationship in the physical world. [3] Rickert proposed the division of nature science and cultural science, and strictly distinguished them with material and form. According to the classification principle of material, the object of natural science is nature, but the object of cultural science is culture and value. According to the classification principle of form, nature science interests in discovering common connection and rules. These rules will be valid for all kinds of things and phenomena, so we must adopt a "general method" to study nature science; Cultural science examines them own object from the viewpoint of value and evaluation. Therefore, it is necessary to use "individual accounting method" to study them own object. [4]

However, these two ideas (to imitate natural science to study humanities or to strictly distinguish human science from nature science) have a common characteristic that natural science can find rules or causal relation about nature. It is generally believed that the laws of science have three main 
characteristics, which are universal, monism, and accuracy. The so-called universality of the scientific laws refers to the same rules will function in the same way at any time and any place, that is to say, it will not produce different results because of the changes of time and place. The so-called monism refers to all the rules could eventually be simplified as a rule, therefore scientific progress in a large extent performance for a large amount of reduced to a smaller number of rules. Einstein had intended to simplify all the laws of physics as a rule. The accuracy refers that people can discover the precise description of the motion of various objects, objects move always as revealed by these principles, rather than to show that kind of movement in most of the time or in the form of average. [5] Renowned scientists Laplace with a optimistic spirit reflects the rules of the world, he thinks present state of the universe is past results and future reasons. If a kind of intelligence can know nature of all strength and the various objects` location of each other, we can use a simple formula to show the various motion of celestial body and atom, so "there is no what is uncertain, the future will be like the past appearing in front of him." [6] In Laplace's world, all things are decided, no chance, no choice, no uncertainty. The role of natural science is to sum up some simple formulas to explain the world in the process of understanding the world. These formulas will constitute the scientific laws.

Because of the universality, monism and accuracy of scientific laws, so it can perform a very important function, that is to effectively predict the future events as Laplace hoped. In theory, the so-called prediction refers to the preview with the strict and quantitative form what will happen under specific conditions. The typical form of prediction is: if A is true, then B is true. It is thought that this prediction is not made, it is built based on the repeatability of test or observation, and it can draw a logical conclusion based on scientific theory.

\section{The Instability of Scientific Prediction}

The famous physicist Niels Bohr said: "prediction, especially on predicting the future, it is very difficult." Why it is so difficult? Here are the reasons mainly include the following aspects. First of all, scientific discovery is concluded in the ideal condition of the laboratory through a variety of means of observation, and this ideal state in the natural process does not exist. Secondly, if we are able to admit that Leibniz's conclusion, that is, there are not existing two same leaves in the world, then we should admit another conclusion that the world are not existing two same natural processes. Since two same natural processes don't exist, we only see the reasons, in the process of the development of things exist many unpredictable factors, and a variety of differences, it is difficult to predict the direction of something's development. Thirdly, we have mentioned the typical form of scientific prediction in the above text: if $A$ is true, then $B$ is true. It should be said in natural processes, A and B are not directly connected in the closed state, but influenced by many external factors and have many intermediate links. In this indirect convergence process, we do not know what will happen, also cannot say A can inevitably lead to B. The above reasons lie in the logic of scientific discovery, and it is difficult to eradicate. Therefore, "Instead of the term 'reliability', other terms are sometimes used with regard to either theories or predictions - for instance, 'probability', 'weight', 'strength', 'degree of confirmation', etc." [7]

Therefore, scientific prediction can only be presented in the form of possibility. British historian, E. H. Carr said after carefully studying the logic of science: "As we have seen, scientists are no longer so eager as they used to be to talk about the laws of nature. The so-called laws of sciences which affect our ordinary life are in fact statements of tendency, statements of what will happen other things being equal or in laboratory conditions. They do not claim to predict what will happen in concrete cases." [8] Carr illustrated an example to explain this case. If two or three children in the school had measles, , it is beyond dispute that you will come to the conclusion that the disease will spread to others; if you are willing to call it the prediction in this degree, it can be completely established. But you can't make predictions for your particular situation that Mary and Tom would have the disease. On the other hand, with the development of human practice and science, complex science and complexity thinking emerged both in science and philosophy. Complexity thinking breaks through the mechanism, reductionism, the naive realism and determinism worldview of 
Newtonian physics, and reveals the movement of objects with nonlinear, systematic, openness and procedural characteristics, and reveals the uncertainty and relativity of various complex phenomena.

Based on the above, we can see that, according to the laws of scientific prediction has great limitations and instability, the prediction about specific circumstances and complex problems just be presented as the form of possibility, and does not have the inevitable trend. Scientific prediction may be a fluke, but not always successful. Therefore, to predict the future is not the main task of scientific research, also not the main function of scientific laws. The main functions of scientific laws should be to response effectively for emergencies and all kinds of practical problems, and to find the effective path of implementing human will and meeting the need of human beings. In a word, its main function is to intervene and control the natural process, so that make the natural process to go forward along the direction of the human will.

\section{The Scientific Law is A Roadmap to Implement the Human Will in Nature}

What kind of relationship is on earth between the scientific laws and the human will? We believe that the so-called scientific law is a roadmap to implement the human will in nature. Put it bluntly, there is a close relationship between scientific laws and human will. The scientific laws are effective methods and routes that found in the long-term practice, meeting their needs and carrying out of their own volition. The main reasons are the following several aspects:

Firstly, people's needs are the driving force of scientific development. Engels once thought that: "Technique largely depends on the state of science, science depends far more still on the state and the requirements of technique. If society has a technical need, that helps science forward more than ten universities." [9] This sentence revealed the dynamic mechanism of the scientific development. People have a need first, then people use scientific way to meet these needs; therefore, human will runs through scientific development from the beginning to the end. Scientific law is proposed in order to meet the requirements of the human will. Human's need is the basic pointer of scientific development. If not to meet the needs of human beings, it will lose the value of research and development. The human's needs can not do a narrow understanding that is not able to understand only from increasing the economic benefit of humanity or obtain actual effect. In addition, from the view of the psychological needs of people, it includes to meet the desire for their own curiosity and knowledge. Out of these needs, the science will be impossible to move a small step forward.

Secondly, scientific and technological innovation is an effective way to implement the human will in nature. Scientific innovation basically can behave in two aspects, one is the innovation of object, namely finding and producing a kind of new things, such as Madame Curie discovered the element radium. Second is the innovation of method, namely not to find something new, but to take different methods and technical route to achieve the same effect, such as improvement in the industrial production lines and workers` operation method. What is the essence of the innovation of object? Hu Shen, the Chinese famous scholar, once described the life world with poetic words, "since human appeared on the earth to the present, great changes have taken place on the face of nature: many barren land had turned into fertile land, the canal had emerged at the place there is not a river originally; air planes are flying in the sky, trains are running on the ground, ships are sailing in the ocean; there are both city and village everywhere; factories, mines and railways can be seen in many places; people enjoy a lot of things that didn't exist in the past world at all" [10] Planes, trains, ships, factories, mines and other things " that didn't exist in the past world at all ", each of them is the significant innovation in the history of human science and technology. the essence of these innovation is to invent and create something new to satisfy human needs and carry human will out in the nature. If there is no human will to participate in, only the natural process, we can believe it is impossible to produce a copper spoon from the nature even after millions of years of development process. The essence the method innovation is same as the innovation of object. The difference is to use a stupid way to build a house in the past, after a method innovation, people can use more simple and more flexible way to build this house, which greatly accelerates the process of human transformation of nature.

Thirdly, to seize the anomalies and chance factors in the experiment is an important way to carry 
human will out in nature. Wang Da-heng, a Chinese famous optical scientist, once in an article thought: "the discovery of anomalies expresses which contain something new; unexpected abnormal phenomenon is often the spring of discovering new things and new rules. ...In fact, many scientific discoveries that have won the Nobel Prize have been raised by the accidental discovery. His discovery caused the advance in a large-scale or a field of science." [11] Obviously, abnormal is set up relatively to normal; it refers to those things that do not appear in the normal state. The anomalies may only appear once or twice times in the normal natural process, and then on, it will not appear again. Cognitive results obtained for these abnormal or accidental things obviously can not be said to reflect the objective natural process. Its essence is to catch and amplify the anomalies and chance factors in nature (more accurately say is the laboratory), then contribute its service for human will.

Fourthly, the mandatory technical route makes human will distort the natural process. Sartre once said in an article named the Legend of Truth: "they poured debris into a mold, heating, freezing, blending, cutting; they tried to use the tamed power to decompose them, just like a secret agent planted between prisoners in order to subdue a prisoners who refused to confess. They called the relationship observed in a machine and a natural production as the law. The prisoner confessed something that he was asked to admit. What would you do if you were in his place?" [12] Human can crush the world's most hard material, also can shaping the most soft material; people can clone a variety of living being, also can make mice grow human's ears; people can destroy a city in an instant, even a nation or the earth, also can rebuild a city in a pile of rubble... In the face of these facts, people can't help to think, which is more powerful between the natural law and the human will? It can be said that before the mandatory measures promoted by the human will, the trajectory of natural objects always can be changed.

Fifthly, the natural process reflected in the human conceptual system is always permeated with human will. We always have some questions the human conceptual system, such as: could we use various concepts to express all of the observation and experience? Is there one-to-one correspondence between the natural objects and our concept? How can we express our new findings when there is no relation to the above question? The answers should be negative for the first two problems. Because language always exists some defects, we have not enough words to express many things, such as some of the feeling of the human heart, terror, pain, sadness, are difficult to express out in words. So in these cases, people often say "don't speak" or "here silent wins audio". In addition, there are some simple concepts can not be defined, such as "salty" or "red", as well as the concept of gravity in the natural sciences, etc.. As long as people acknowledge that there is something humans have yet to know in nature, the one-to-one correspondence between the object and the concept is unsupported.

The answer to the third question is the key to the problem that we need to explain. The framework of human concept is set or stable. It is the result of human past practice and a prerequisite for people to engage in new practice. Scientific research is to put things or events in nature into human conceptual framework, in other words, it is to use the human conceptual framework to integrate nature, then making it obtain order and meaning. When the observed phenomenon in the experiment does not exceed the original conceptual framework, it is easy for the identity; when a new phenomenon beyond the original conceptual framework, the scientific attitude is to accept the phenomenon first, and then to think of ways to interpret and explain it. The first approach is not to present new concepts, and to make it fuse together with the old concept framework; the other way is to put forward some new concepts, the new concepts are not from heaven, but from the original conceptual framework's extension, its legitimacy is the justification with other concepts or scientific law. Both of the above paths, they can't get rid of the constraint by the original conceptual framework; we won't believe these two paths can reflect the real motion process of object faithfully, accurately and without distortion. No matter how scientific explanation operates, on the one hand due to the human conceptual system's congenital defects, on the other hand due to the justification and support of the original concept system to the new interpretation, so the scientific explanation is always the transformation, we would put human will into the real 
movement of natural object.

\section{Acknowledgements}

[ Foundation item] Sponsored by Hebei College Humanities and Social Science Research Youth Talent Project "On the Problem of the Truth of Historical Narrative” (project number: BJ2014100).

\section{References:}

[1] G. W. F. Hegel, The Phenomenology of Mind, Dover Publications, Inc., New York, 2003: 3.

[2] B. Russell, Portraits from memory and Other Essays, Simon and Schuster, New York, 1956: 15.

[3] W. Dilthey, Einleitung in Die Geisteswissenschaften, China City Press, Beijing, 2003: 234-275.

[4] H. Rickert, Kulturwissenschaft und Naturwissenschaft, the Commercial Press, Beijing, 1986: II - III.

[5] L. J. Lafleur, On the Nature of Scientific Law, The Scientific Monthly, 1952, 74(5): 248-249.

[6] R. S. Butts, A Primer on Determinism, D. Reidel Publishing Company, Dordrecht, 1986: 7.

[7] R. Carnap, Theory and Prediction in Science, Science, New Series, 1946, 104 (2710): 520.

[8] E. H. Carr, What Is History?, translated by Chen Heng, the Commercial Press, Beijing, 2007: 163.

[9] K. H. Marx, F. Engels, The Collected Works of Marx and Engels, 2nd edition, translated by the Central Compilation \& Translation Bureau, People’s Publishing House, Beijing, 1995: 731-732.

[10] HU Shen, YU Guang-yuan, WANG Hui-de, Lectures on the Basic Knowledge of Social Science (volume I), People’s Publishing House, Beijing, 1954: 1.

[11] WANG Da-heng, On the Scientific Spirit, China Metrology, 2008, (4): 5.

[12] Jean-Paul Sartre, Les Oeuvres Philosophiques de Sartre, translated by PAN Pei-qing, etc, Anhui Literature and Art Publishing House, Hefei, 1998: 14. 